\title{
SUSCETIBILIDADE À INFECÇÃO PELO SCHISTOSOMA MANSONI, DE BIOMPHALARIA GLABRATA E BIOMPHALARIA TENAGOPHILA DO DISTRITO FEDERAL, BRASIL *
}

Carlos Everaldo A. Coimbra Jr.**

COIMBRA JR., C.F.A. Suscetibilidade à infecção pelo Schistosoma mansoni, de Biomphalaria glabrata e Biomphalaria tenagophila do Distrito Federal, Brasil. Rev. Saúde públ., S. Paulo, 15:485-9, 1981.

RESUMO: $\mathrm{E}$ feito um estudo sobre a suscetibilidade de B. glabrata e B. tenagophila, coletados em Brasília, DF (Brasil), à infecção por $\mathbf{S}$. mansioni, visando determinar a importância epidemiológica dessas espécies na transmissão da doença na região. Relaciona-se a localização e as condiçôes dos criadouros com a origem dos casos autóctones conhecidos.

UNITERMOS: Esquistossomose mansônica. Schistosoma mansoni. Biomphalaria glabrata. Biomphalaria tenagophila.

\section{INTRODUCGAO}

Em pesquisas realizadas na cidade satélite de Planaltina, DF, durante 0 ano de 1978, como parte de um programa de Medicina Comunitária que havia na região foram detectados sete casos autóctones de esquistossomose em um bairro por nós trabalhado nesta cidade (Barbosa e Coimbra Jr. ${ }^{3}, 1979$ ).

Esses achados suscitaram pesquisas sobre a fauna malacológica da região visando aspecto tanto da biologia como da epidemiologia, com o objetivo de determinar a importância das espécies de Biomphalaria do Distrito Federal na transmissão da esquistossomose, assim como alguns aspectos humanos que também pudessem estar relacionados com a epidemiologia da doença na região.

Estudos sobre a suscetibilidade dos hospedeiros intermediários à infecção por dife- rentes cepas de $S$. mansoni têm sido realizados por diversos autores. Estes, tornam-se importantes à medida que forneçam dados que sirvam como subsidios para trabalhos mais abrangentes que visem determinar o potencial de uma região para se tornar endêmica.

\section{MATERIAL E METODOS}

As áreas trabalhadas foram: o rio Mestre d'Armas, que atravessa a cidade de Planaltina, DF e onde foram encontrados exemplares de Biomphalaria glabrata infectados naturalmente por $S$. mansoni (Barbosa e Coimbra Jr.3, 1979), o rio Preto e o córrego São José, ambos próximos ao núcleo rural Curral Queimado e às chácaras hortigranjeiras do Núcleo Bandeirante, banhadas pelo rio Vicente Pires.

* Trabalho realizado com auxilio do Conselho Nacional de Desenvolvimento Científico e 'Tecnológico - CNPq.

** Bolsista do CNPq - Núcleo de Medicina Tropical e Nutrição - Universidaje de Brasília .. 70910 - Brasilia. DF - Brasil. 
COIMBRA JR., C.E.A. Suscetibilidade à infeçãa pelo Schistosoma mansoni, de Biomphalaria glabrata e Biomphalaria tenagophila do Distrito Federal, Brasil. Rev. Saúde públ., S. Paulo, $15: 485-9$, 1981 .

Os moluscos coletados eram transportados ao laboratório onde era feita a identificação dos exemplares. Após serem identificados, eram colocados durante duas horas sob foco de luz e então observados na lupa para procura de cercárias. Os que davam resultado negativo eram transferidos para um aquário. Este possuia substrato de cascalho de mármore e era plantado com Vallisneria sp., Elodea canadensis e $\mathrm{Ca}$ bomba sp. $\mathrm{Na}$ superfície eram colocados pedaços de isopor para que recebessem as desovas dos caramujos. A alimentação era constituida por ração "Aquariol", alface e cenoura cortada.

Os exemplares de Biomphalaria, usados nos experimentos, eram nascidos em laboratório, à partir de matrizes coletadas em campo.

Para a infecção, os caramujos eram expostos aos miracidios individualmente, em copinhos plásticos contendo $5 \mathrm{ml}$ de água de aquário e cerca de 15 miracídios.

Os miracídios eram obtidos à partir de fígados de camundongos albinos infectados cm laboratório com cepa de $S$. mansoni obtida de paciente nascido em Recife, Pernambuco, e que sempre viveu na região. Para a concentração dos miracídios seguiu-se a técnica de Barbosa e col. ${ }^{1}$ (1960).

Os caramujos foram infectados em lotes, tendo como controle B. glabrata obtidos no Centro de Pesquisas Aggeu Magalhães, em Recife, pertencentes à cepa de Paulista, Pernambuco, por ser esta cepa considerada altamente suscetivel à infecção pelo miracídio de S. mansoni.

Foram realizados 5 grupos de experimentos:

1 - 25 B. glabrata do DF e 25 B. glabrata de Pernambuco;

2 - 71 B. glabrata do DF e 65 B. glabrata de Pernambuco;

3 - 78 B. glabrata do DF e 66 B. glabrata de Pernambuco;

$4-30$ B. tenagophila do DF e 30 B. glabrata de Pernambuco;

5 - 21 B. tenagophila do DF e $21 B$. glabrata de Pernambuco.

Ao $30^{\circ}$ dia após a tentativa de infecção os caramujos eram examinados. Para tal. eram os mesmos colocados individualmente em copinhos plásticos e expostos à iluminação artificial intensa por duas horas, quando então eram examinados. Os que se apresentassem eliminando cercárias eram suprimidos e os que ainda estivessem negativos eram devolvidos à seus aquários. Com 40 dias eram outra vez examinados e os que ainda se apresentassem negativos eram reexaminados com 60 dias, quando então eram esmagados para procura de cercárias.

\section{RESULTADOS}

A B. glabrata do Distrito Federal se infectou em $54,4 \%$, enquanto que o controle se infectou em $91,4 \%$.

Quanto à $B$. tenagophila, não se conseguiu infectar nenhum exemplar, ao

T A B E L A

Indices de Infeç̧ão pelo Sohistosoma mansoni para as cepas de Biomphalaria glabrata e $B$. tenagophila do Distrito Federal, em comparação com $B$. glabrata de Paulista, Pernambuco, usada como controle, 1980.

\begin{tabular}{lccc}
\hline $\begin{array}{c}\text { Espécies } \\
\text { de } \\
\text { caramujos }\end{array}$ & $\begin{array}{c}\text { Caramujos } \\
\text { expostos à } \\
\text { infeç̧̃o (total) }\end{array}$ & $\begin{array}{c}\text { Caramujos } \\
\text { examinados } \\
\text { (vivos) }\end{array}$ & Positivos \\
\hline B. glabrata & 174 & 101 & $55(54,4 \%)$ \\
controle & 156 & 70 & $64(91,4 \%)$ \\
$B$ tenagophila & 51 & 48 & - \\
controle & 51 & 47 & $44(93,6 \%)$ \\
\hline
\end{tabular}


COIMBRA JR., C.E.A. Suscetibilidade à infeção pelo Schistosoma mansoni, de Biomphalaria glabrata e Biomphalaria tenagophila do Distrito Federal, Brasil. Rev. Saúde públ., S. Paulo, $15: 485-9,1981$.

passo que o controle se infectou em 93,6\%.

Os resultados estão resumidos na Tabela.

\section{COMENTARIOS E CONCLUSOES}

A manutenção de focos ativos de transmissão da esquistossomose está relacionada a diversos fatores que não são apenas o tremátodo parasita e a presença de moluscos hospedeiros intermediários mas, principalmente, a existência de populações humanas de baixo nível sócio-econômico vivendo em densidade suficiente para poluir as coleçōes aquáticas de onde se servem para fins domésticos e profissionais.

A expansão da esquistossomose tem se dado através de migrações das populações de baixa renda a partir do Nordeste para outras regiões do Brasil ( $\mathrm{CNPq},{ }^{4}$ 1978). No Distrito Federal, grandes contingentes de migrantes nordestinos aqui se estabeleceram, em geral mantendo-se em condições habitacionais e sanitárias precárias.

A primeira referência a esquistossomose na região do DF é de Crespo e col.5 (1965), que em um afluente do Rio Preto encontraram Biomphalaria glabrata com infecção natural de $10,26 \%$.

A ocorrência de espécies de Biomphalaria no Distrito Federal está relacionada com diferentes bacias hidrográficas. A espécie B. glabrata é encontrada nos cursos d'água pertencentes à bacia do rio São Francisco (ex. rios Mestre d'Armas, Preto, São José, Piriri, etc.); B. tenagophila ocorre nos rios pertencentes à bacia do rio Paraná (ex. São Bartolomeu, Vicente Pires, etc.) e $B$. straminea está presente nos cursos d'água que correm para o Norte. Vale a pena observar que $B$. tenagophila e $B$. straminea foram observados vivendo juntos em diversos cursos d'água que desembocam no Lago Paranoá de Brasília (Monteiro e Dias 8 , 1980).

As áreas onde foram encontrados $B$. glabrata eram em geral brejos naturais formados pelo transbordamento do curso d'água principal. Nestes brejos a vegetação aquática é abundante e constituída principalmente por Nymphaea (Nymphacacea), e Etchornia (Pontederiaceae), além de rica fauna aquática composta por artrópodos, hirudineos, anfíbios, pequenos peixes, aves palustres e diferentes gêneros de caramujos como Drepanotrema, Physa e Pomacea.

No brejo formado pelo rio Mestre d'Armas, no Bairro Nossa Senhora de Fátima em Planaltina, além das condições ecológicas que favorecem à transmissão da doença. vive em sua margem esquerda uma população de baixo padrão sócio-econômico em precárias condições de habitaçăo e saneamento. Nesta população foi constatada alta prevalência de enteroparasitoses e inclusive diversos casos de esquistossomose, sendo sete desses considerados como autóctones (Barbosa e Lavor ${ }^{2}$ 1977, Barbosa e Coimbra Jr. ${ }^{3}$ 1979).

$\mathrm{Na}$ região do núcleo rural Curral Queimado, banhado por dois cursos d'água principais - Rio Preto e córrego São José (afluente do primeiro) foi observada copiosa população de $B$. glabrata.

Em inquérito coproparasitológico neste núcleo rural (Coimbra Jr. 1980)* foram localizados três casos suspeitos de serem autóctones, pois se tratavam de rapazes entre 15 à 22 anos nascidos na região e que, segundo eles, só sairam do Distrito Federal para irem a uma festa em Unai. Minas Gerais.

Ainda na mesma região, Magalhães (1966) encontrou $B$. glabrata em dois focos com infecção por $S$. mansoni de $2,7 \%$ e $3,3 \%$ e dois casos humanos tidos como autóctones.

As chácaras hortingranjeiras onde foram coletados os $B$. tenagophila nas valas de irrigação situam-se na margem direita do córrego Vicente Pires, afluente do córrego Riacho Fundo que desemboca no Lago Paranoá de Brasilia. Nestas valas é ósservada vegetação aquática e semi-aqlática composta por Gramineas e Ciperáceas, que contribuem para o sombreamento das mes-

* Relatório de Atividades, set/1979 a março/1980, apresentado ao CNPq - Dados inéditos. 
COJMBRA JR., C.E.A. Suscetibilidade à infecção pelo Schistosoma mansoni, de Biomphalaria glabrata e Biomphalaria tenagophila do Distrito Federal, Brasil. Rev. Saúde púbt., S. Paulo, $15: 485-9,1981$.

mas. Nestes locais há densa população de caramujos mas no entanto, não existem referências sobre casos de esquistossomose entre os que ai moram.

Os índices de infecção obtidos para $B$. glabrata $(54,4 \%)$ e $B$. tenagophila do Distrito Federal vem confirmar observações feitas por Magalhães (1970), que apesar de trabalhar com menor numero de exemplares e não utilizar controle, conseguiu indices de infecção semelhantes aos obtidos nesse trabalho - $54 \%$ para $B$. glabrata e nenhum $B$. tenagophila positivo.

Em vista desses dados vê-se que as condições ecológicas ideais para o estabelecimento de um foco ativo de transmissão da doença no Distrito Federal existem pelo mienos nas áreas onde se encontram populações de $B$. glabrata, haja vista o bom indice de infecção $(54,4 \%)$ que obtivemos experimentalmente. Além disso, o baixo nível sócio-econômico da população nas áreas pesquisadas contribui favoravelmente para que a transmissão desta parasitose se estabeleça na área. $O$ que ainda falta para que isto ocorra é uma maior concentração populacional nas mesmas condições em que se encontram os individuos que vivem atualmente na região, ou seja, em precárias condições de higiene e habitação.

Quanto à $B$. tenagophila podemos dizer $\mathrm{com}$ base nos trabalhos experimentais que a mesma se mostrou resistente à infecção por $S$. mansoni e que portanto, não representa perigo sob o ponto de vista epidemiológico, embora deva ser lembrada a possibilidade de adaptação de cepas de $S$. mansoni à cepa local de $B$. tenagophila (Paraense e Corrêa, ${ }^{9}$ 1963).

No Núcleo Bandeirante, onde se localizam as chácaras hortigranjeiras, existe população vivendo em condições promíscuas de saneamento. No entanto, a cepa de B. tenagophila encontrada no local se mostrou résistente à infecção por $S$. mansoni. Já na região da cidade-satélite de Planaltina e na região do rio Preto, onde se encontram B. glabrata suscetíveis, a população humana é mais dispersa. Porém, com a incrementação dos projetos imobiliários e loteamento na região, a densidade populacional tem aumentado rapidamente, principalmente ao lengo dos cursos d'água, o que nos leva a crer que esta seja uma área de eleição para o estabelecimento de um foco ativo de transmissão da esquistossomose no Distrito Federal. Estudos epidemiológicos mais amplos tornam-se relevantes para que seja possivel acompanhar de perto a doença e assim impedir que a mesma se dissemine $e$ se torne endêmica na região.

\section{AGRADECIMENTO}

Ao Prof. Frederico Simões Barbosa, da Faculdade de Ciências da Saúde, da Universidade de Brasília pela orientação do trabalho.
COIMBRA JR., C.E.A. [Susceptibility of Biomphalaria glabrata and Biomphalaria
tenagophila of the Federal District of Brazil to infection by Schistosoma man-
soni]. Rev. Saúde públ., S. Paulo, 15:485-9, 1981.

ABSTRACT: The susceptibility of Bimphalaria glabrata and Biomphalaria tenagophila, collected in the Federal District of Brazil, to infection by Schistosoma mansoni is here studied. The author also relates the geographical distribution of the snails' habitats and their living conditions to the source of the autochthonous cases known in the Federal District.

UNITERMS: Schistosomiasis, DF, Brazil. Schistosoma mansoni. Biomphalaria glabrata. Biomphalaria tenagophila. 
COIMBRA JR., C.E.A. Suscetibilidade à infeção pelo Schistosoma mansoni, de Biomphalaria glabrata e Biomphalaria tenagophila do Distrito Federal, Brasil. Rev. Saúde públ., S. Paulo, $15: 485-9,1981$.

\section{REFERENCIAS BIBLIOGRAFICAS}

1. BARBOSA, F.S. \& COIMBRA Jr., C.E.A Esquistossomose mansônica autóctone no Distrito Federal. Brasil. Rev. Saude públ., S. Paulo, 13:108-12, 1979.

2. BARBOSA, F.S. \& LAVOR, A.C.H. Esquistossomose autóctone no Distrito Federal. In: Congresso Brasileiro de Higiene, 19\%, São Paulo, 1977. Resumo dos trabalhos. São Paulo, 1977. t. 11.2 .

3. BARBOSA, F.S. et al. Manual de malacologia médica. Salvador, Fundação Gonçalo Muniz, 1960.

4. CRESPO, V.M. et al. Esquistossomose em áreas do Distrito Federal. Rev. bras. Malar., 17:367-9, 1965.

5. MAgalhães, L.A. Estudo do comportamento da cepa de S. mansoni de Brasilia. Hospital, Rio de Janeiro, 77:273-82, 1970.
6. MAGALHAES, L.A. Moluscos planorbideos do Distrito F'ederal. Campinas, 1966. [Tese de Doutoramento - Faculdade de Medicina da Universidade de Campinas].

7. MONTEIRO, W. \& DIAS, M.L.F. Distribuição dos moluscos pulmonados aquâticos e identificação dos planorbídeos da Bacia co Lago Paranoá, Brasilia (Mollusca, Gastropoda). Rev. bras. Biol, 40:67-74, 1980 .

8. PARAENSE, W.L. \& CORREA, I.R. Susceptibility of Australorbis tenagophilus to infection with Schistosoma mansoni. Rev. Inst. Med. trop. S. Pauto, 5:23-9, 1963.

Recebiao para publicação em 26/05/1981

Aprovado para publicação em 21/07/1981 